\title{
Self-microemulsifying drug delivery systems of Moringa oleifera extract for enhanced dissolution of kaempferol and quercetin
}

\author{
NAMFA SERMKAEW ${ }^{1,2, *}$ \\ THIPAPUN PLYDUANG ${ }^{1,2}$ \\ ${ }^{1}$ School of Pharmacy, Walailak \\ University, Nakhon Si Thammarat \\ 80161, Thailand \\ ${ }^{2}$ Drug and Cosmetics Excellence Center \\ Walailak University, Nakhon Si \\ Thammarat 80161, Thailand
}

Accepted March 15, 2019 Published April 8, 2019

\begin{abstract}
The aim of the present study was to develop self-microemulsifying drug delivery systems (SMEDDS) of the extract of Moringa oleifera, a herbal medicinal plant. Kaempferol and quercetin, the flavonoids present in the leaf extract of $M$. oleifera, were chosen as markers for quantification. The optimized formulation of SMEDDS consisted of propylene glycol dicaprylocaprate, polysorbate 80, and polyethylene glycol 400 (PEG 400) in a percentage ratio of 20:60:20 ( $\mathrm{m} / \mathrm{m})$. SMEDDS emulsified immediately (within $20 \mathrm{~s}$ ) after dilution in water, resulting in transparent microemulsions with a droplet size of $49 \mathrm{~nm}$. SMEDDS could increase the solubility of kaempferol and quercetin to nearly $100 \%$ within $15 \mathrm{~min}$, whereas only a $30 \%$ improvement in solubility was achieved in the case of crude extract. These results demonstrated SMEDDS to be a promising strategy to improve the solubility of $M$. oleifera extract-derived drugs, which, in turn, could prove beneficial to the herbal medicine field.
\end{abstract}

Keywords: Moringa oleifera, self-microemulsifying, crude extract, kaempferol, quercetin

Moringa oleifera is a medicinal plant that belongs to the family Moringaceae and is widely cultivated in subtropical and tropical regions including Thailand. M. oleifera is rich in beneficial nutrients; for example, its leaves are a rich source of several phytochemicals, including proteins, essential amino acids, and many kinds of vitamins and minerals, such as vitamin A, B, C, and E, iron, zinc, calcium, and potassium (1, 2). Its antioxidant activity is attributed to the presence of flavonoids and phenolic compounds (3). Different extracts of $M$. oleifera have also other pharmacological effects, such as anti-hyperglycemic (4), hypolipidemic, antiatherosclerotic (5) and anticancer activities (6-8), owing to which it is widely used as a herbal drug. In the present study, two compounds with pharmacological activities, namely, kaempferol and quercetin, present in the leaf extract of $M$. oleifera, were selected as markers for quantification of phenolic compounds. However, poor aqueous solubility of these compounds results in their low oral bioavailability and absorption. For

\footnotetext{
* Corresponding author; e-mail: namfa.se@wu.ac.th
} 
N. Sermkaew and T. Plyduang: Self-microemulsifying drug delivery systems of Moringa oleifera extract for enhanced dissolution of kaempferol and quercetin, Acta Pharm. 70 (2020) 77-88.

example, studies have reported kaempferol to be poorly soluble in water $\left(440 \mu \mathrm{g} \mathrm{mL}^{-1}\right)(9)$, with bioavailability of approximately $2 \%$ in rats (10). Similarly, water solubility of quercetin was only $10.28 \mu \mathrm{g} \mathrm{mL}^{-1}$ at $25^{\circ} \mathrm{C}$ (11). Its oral bioavailability has been reported to be less than 17 and $1 \%$ after oral administration to rats and humans, respectively $(12,13)$.

Several strategies have been developed to improve the solubility and oral absorption of kaempferol and quercetin, such as phospholipid complexes $(14,15)$ and nano-emulsions $(16)$. Lipid-based drug delivery systems are among the most potential strategies to improve the solubility and oral bioavailability of drugs. Self-emulsifying drug delivery systems (SEDDS) have been frequently used to overcome the obstacles of low oral absorption of compounds such as biopharmaceutical classification system (BCS) class II and class IV drugs. SEDDS are transparent isotropic mixtures composed of oil, surfactant, and/or co-solvent or co-surfactant that can easily self-emulsify to form oil/water $(\mathrm{o} / \mathrm{w})$ emulsions on coming in contact with a liquid medium such as the gastrointestinal (GI) fluid by gentle agitation provided by the GI motility. The main advantage of SEDDS is that they enhance the oral bioavailability of the drug by avoiding the dissolution step, considered to be the rate-limiting step in drug absorption. The size of emulsion droplets of SEDDS varies from 100 to $300 \mathrm{~nm}$, whereas the size of the transparent microemulsion formed by the self-microemulsifying drug delivery system (SMEDDS) is less than $50 \mathrm{~nm}(17,18)$. Thus far, no literature is available on the development of self-microemulsifying systems of $M$. oleifera extract.

The aim of the present study was to develop SMEDDS formulations of M. oleifera crude extract to enhance the solubility and dissolution of its two active constituent markers, kaempferol and quercetin. The physical properties such as self-emulsification performance, microemulsion droplet size, polydispersity index (PDI), and in vitro dissolution were also determined.

\section{EXPERIMENTAL}

\section{Materials}

Kaempferol ( $\geq 97.0 \%$ ) and quercetin (pharmaceutical secondary standard) were purchased from Sigma-Aldrich (Singapore). Crodamol ${ }^{\mathrm{TM}}$ PC (propylene glycol dicaprylocaprate) was acquired from Croda (Spain). Tween ${ }^{\circledR} 80$ (polysorbate 80 , polyoxyethylene sorbitan monooleate) and polyethylene glycol 400 (PEG 400) were purchased from B.L. Hua \& Co. Ltd. (Thailand). Cremophor ${ }^{\circledR}$ RH 40 (PEG-40 hydrogenated castor oil) was purchased from BASF (Germany). Acetonitrile (high-performance liquid chromatography [HPLC] grade) was purchased from RCI Labscan (Thailand). All other chemicals were of analytical grade. M. oleifera leaf powder was purchased from Lopburi province, Thailand.

\section{Extraction of $M$. oleifera leaf extract}

Three hundred grams of M. oleifera leaf powder was extracted with $1500 \mathrm{~mL}$ of $95 \%$ ethanol for $1 \mathrm{~h}$ using the reflux method. The liquid extract was filtered through a filter paper, and the remaining material was re-extracted using the same protocol. Ethanol was removed using a rotary evaporator and a vacuum oven for 3 days. The extract was kept in the refrigerator $\left(2-8^{\circ} \mathrm{C}\right)$ in a well-closed glass container. 
N. Sermkaew and T. Plyduang: Self-microemulsifying drug delivery systems of Moringa oleifera extract for enhanced dissolution of kaempferol and quercetin, Acta Pharm. 70 (2020) 77-88.

\section{Determination of free radical scavenging activity of $\mathrm{M}$. oleifera leaf extract}

The free radical scavenging activity of $M$. oleifera leaf extract was determined using the 2,2-diphenyl-1-picryl-hydrazyl-hydrate (DPPH) assay (5). The M. oleifera extract was dissolved in $95 \%$ ethanol to obtain various concentrations (100, 75, 50, 25, 12.5, and $6.25 \mu \mathrm{g}$ $\left.\mathrm{mL}^{-1}\right)$. The extract solution of $100 \mu \mathrm{L}$ was mixed with $100 \mu \mathrm{L}$ of DPPH solution $(24 \mu \mathrm{g}$ $\mathrm{mL}^{-1}$ ) in a 96-well plate. The plate was incubated in the dark for $30 \mathrm{~min}$, following which absorbance at $515 \mathrm{~nm}$ was recorded using a microplate reader. Ascorbic acid was used as the positive control. Free radical scavenging activity was expressed as $I C_{50}$ value, which is the concentration of $M$. oleifera extract that could inhibit $50 \%$ of DPPH radicals. The $I C_{50}$ value could be calculated by plotting different concentrations of the extract against $\%$ inhibition, with the concentration corresponding to $50 \%$ inhibition referring to $I C_{50}$ value.

Percentage of inhibition was calculated using the following equation:

$$
\% \text { inhibition }=\left[1-\left(A_{515} \text { sample } / A_{515} \text { blank }\right)\right] \times 100
$$

where $A_{515}$ sample and $A_{515}$ blank are absorbance values of the sample and blank (95\% ethanol), respectively, at $515 \mathrm{~nm}$.

Determination of kaempferol and quercetin solubility from $\mathrm{M}$. oleifera extract in various solvents

The ability of various solvents, including oils, surfactants, and co-solvents, to dissolve M. oleifera extract was studied. A total of $250 \mathrm{mg}$ of $M$. oleifera extract was added to a microtube containing $1 \mathrm{~mL}$ of each solvent. The mixtures were subsequently vortexed for 10 min and incubated in a water bath under continuous shaking at $37^{\circ} \mathrm{C}$ for $72 \mathrm{~h}$. The microtubes were then centrifuged at $4000 \mathrm{rpm}$ for $20 \mathrm{~min}$ to remove the precipitate. The supernatant obtained was diluted with methanol. Amounts of kaempferol and quercetin dissolved in each solvent were analyzed using HPLC.

\section{Preparation of self-microemulsifying systems of M. oleifera extract}

SMEDDS formulations were prepared using oils, surfactants, and co-solvents possessing a good ability to solubilize the extract. The percentage of oil varied from 10 to $40 \%$ and the ratios of surfactant to co-solvent used were 1:1, 1:3, 2:1, 3:1, and 4:1. The components were mixed to obtain a homogeneous mixture. Each mixture was evaluated for the appearance and self-emulsification ability. The extract $(10 \%, \mathrm{~m} / \mathrm{m})$ was added to the selected SMEDDS, and the mixtures were magnetically stirred until clear SMEDDS formulations were obtained. SMEDDS formulations of $400 \mathrm{mg}$ of $M$. oleifera extract were filled into hard gelatin capsules and kept in a well-closed glass container. They were used in in vitro dissolution tests.

Construction of a ternary phase diagram and evaluation of self-emulsification performance of SMEDDS formulations

The self-emulsification performance of SMEDDS was evaluated by visual assessment. The SMEDDS formulation $(0.2 \mathrm{~mL})$ was mixed with $100 \mathrm{~mL}$ of distilled water. The contents were mixed gently using a magnetic stirrer at a speed of $60 \mathrm{rpm}$. The time taken to self- 
emulsify was recorded, and the appearance of the mixture after emulsification was observed. The self-emulsification performance was scored as a visual grading system. The formulations were scored as Grade I when the microemulsion was formed within less than $1 \mathrm{~min}$. Grade II denoted formation of a microemulsion with an emulsification time of more than $1 \mathrm{~min}$ and less than or equal to $2 \mathrm{~min}$. Grade III referred to microemulsions that took more than 2 min but less than or equal to 4 min to form. Also, Grade IV denoted the forming of emulsion. Formulations were termed Grade $\mathrm{V}$ when no emulsion was formed, with large oil droplets present on the surface. Ternary phase diagrams were plotted to identify self-microemulsification regions according to the self-emulsification visual grading to find optimal ratios of SMEDDS compositions.

\section{Emulsion droplet size analysis}

A 0.2-mL solution of the SMEDDS formulation was dispersed into $100 \mathrm{~mL}$ of distilled water. The contents were mixed gently on a magnetic stirrer for $1 \mathrm{~min}$, following which the droplet size of the emulsion and the polydispersity index (PDI) were determined using a Zetasizer (Malvern Instrument, Malvern, UK).

\section{Dissolution test}

The in vitro dissolution test was performed using the beaker method. Dissolution medium consisted of $20 \mathrm{~mL}$ of simulated gastric fluid ( $\mathrm{pH}$ 1.2) without pepsin. The temperature was kept constant at $37 \pm 0.5^{\circ} \mathrm{C}$. The rotational speed was maintained at $50 \mathrm{rpm}$ using a magnetic stirrer. Dissolution profiles of kaempferol and quercetin SMEDDS formulations filled in hard gelatin capsules were compared to that of the unformulated extract. The test was performed in triplicate.

\section{Quantification of kaempferol and quercetin}

Amounts of kaempferol and quercetin in samples were analyzed using an HPLC system (Dionex, Thermo Fisher Scientific, USA), equipped with a C18 column (VertiSep ${ }^{\text {TM }}$ UPS C18 column; $4.6 \times 250 \mathrm{~mm}, 5 \mu \mathrm{m}$; Ligand Scientific, Thailand). The mobile phase consisted of acetonitrile and $0.1 \%$ phosphoric acid in a ratio of $55: 45$, with a flow rate of $1 \mathrm{~mL} \mathrm{~min} \mathrm{~m}^{-1}$, and injection volume of $20 \mu \mathrm{L}$. The ultraviolet (UV) detector was set at the wavelength of $370 \mathrm{~nm}$. Retention time of kaempferol and quercetin was calculated to be 5.7 and $4.2 \mathrm{~min}$, respectively. The concentration range with good linearity of 0.1 to $5.0 \mu \mathrm{g} \mathrm{mL} \mathrm{m}^{-1}$ showed a correlation coefficient of 0.999 .

\section{RESULTS AND DISCUSSION}

\section{Extraction of $M$. oleifera extract}

The extract of $M$. oleifera leaf was a sticky, dark green, semi-solid product with a yield of $8.81 \%(\mathrm{~m} / \mathrm{m})$. The crude extract consisted of $0.0047 \%$ of kaempferol and $0.0025 \%$ of quercetin. DPPH is considered to be the most popular assay for assessing free radical scavenging activity. The $I C_{50}$ value of the extract determined by the DPPH assay was 59.65 
N. Sermkaew and T. Plyduang: Self-microemulsifying drug delivery systems of Moringa oleifera extract for enhanced dissolution of kaempferol and quercetin, Acta Pharm. 70 (2020) 77-88.

$\pm 0.59 \mu \mathrm{g} \mathrm{mL}{ }^{-1}$, which was lower than that of ascorbic acid $\left(I C_{50}=2.66 \pm 0.01 \mu \mathrm{g} \mathrm{mL}^{-1}\right)$. Lower value of $I C_{50}$ could be attributed to small amounts of antioxidant compounds in the crude extract. The DPPH assay was not conducted for SMEDDS formulations.

\section{Screening excipients and development of SMEDDS of M. oleifera extract}

The ability of various solvents to solubilize M. oleifera extract was evaluated by determining the amount of kaempferol and quercetin that dissolved in each solvent. Solvents were divided into three groups: oil, surfactant, and co-solvent. All excipients could enhance the solubility of kaempferol and quercetin compared to water. Solubility of kaempferol and quercetin in oils was the highest in $\mathrm{Crodamol}^{\mathrm{TM}} \mathrm{PC}$, a propylene glycol-based derivative commonly used in self-microemulsifying formulations (19). Other oils in the study included long-chain triglycerides. Solubility provided by natural oils (sesame oil, olive oil, and soybean oil) was lower than that of Crodamol $^{\mathrm{TM}} \mathrm{PC}$. The solubilizing effect of Crodamol ${ }^{\mathrm{TM}} \mathrm{PC}$ could be attributed to the presence of propylene glycol in it. However, the solubility of kaempferol and quercetin in oleic acid was not significantly different from that of natural oils. Surfactants used in developing SMEDDS should possess a high HLB (hydrophile-lipophile balance) value. Moreover, non-ionic surfactants should be employed owing to less toxicity compared to ionic surfactants. The current study utilized Cremophor $^{\circledR}$ RH 40 and Tween ${ }^{\circledR} 80$ in developing SMEDDS. Cremophor ${ }^{\circledR}$ RH 40 or polyoxyl40-hydrogenated castor oil and Tween ${ }^{\circledR} 80$ have the HLB of 14 to 16 and 15, respectively. Therefore, Crodamol ${ }^{\mathrm{TM}} \mathrm{PC}$ and sesame oil were selected as the oil phase for further development of SMEDDS since they provided the highest solubility to the active compounds. Both Cremophor ${ }^{\circledR}$ RH 40 and Tween ${ }^{\circledR} 80$ were used as surfactants to develop SMEDDS since they exhibited comparable solubilizing efficiency for kaempferol and quercetin. PEG 400 and propylene glycol exhibited good ability to solubilize the active compounds although PEG 400 provided higher ability to solubilize. Thus, both of these were employed as co-solvents (Table I). PEG 400 is more hydrophobic than propylene glycol; therefore, the higher solubility of kaempferol and quercetin in PEG 400 could be attributed to greater hydrophobic interactions of the active compounds with the co-solvent (20).

Mixtures of three ingredients, including oil, surfactant, and co-solvent, with varying percentage ratios were prepared. Formulation mixtures were divided into eight groups: (1) sesame oil, Cremophor ${ }^{\circledR}$ RH 40, and PEG 400; (2) sesame oil, Cremophor ${ }^{\circledR}$ RH 40, and propylene glycol; (3) sesame oil, Tween ${ }^{\circledR} 80$, and PEG 400; (4) sesame oil, Tween ${ }^{\circledR} 80$, and propylene glycol; (5) Crodamol $^{\mathrm{TM}}$ PC, Cremophor ${ }^{\circledR} \mathrm{RH} 40$, and PEG 400; (6) Crodamol ${ }^{\mathrm{TM}} \mathrm{PC}$, Cremophor $^{\circledR}$ RH 40, and propylene glycol; (7) Crodamol $^{\mathrm{TM}}$ PC, Tween ${ }^{\circledR}$ 80, and PEG 400; and (8) Crodamol $^{\mathrm{TM}} \mathrm{PC}$, Tween ${ }^{\circledR} 80$, and propylene glycol.

Various ratios of oil, surfactant, and co-solvent were evaluated for homogeneity, emulsification, phase separation, and droplet size. Homogeneity and phase separation of the prepared ingredient combinations were evaluated immediately after preparation and after $24 \mathrm{~h}$. Inappropriate ratios might result in an inhomogeneous mixture. Therefore, after mixing the ingredients, phase separation of the system had to be observed. Stable SMEDDS should maintain the isotropic and homogeneous appearance during shelf life. Only formulations exhibiting a clear homogeneous solution and no phase separation were used for further experiments. 
N. Sermkaew and T. Plyduang: Self-microemulsifying drug delivery systems of Moringa oleifera extract for enhanced dissolution of kaempferol and quercetin, Acta Pharm. 70 (2020) 77-88.

Table I. Solubility of kaempferol and quercetin in various vehicles

\begin{tabular}{|c|c|c|}
\hline Solvent & $\begin{array}{c}\text { Kaempferol } \\
\text { Mean } \pm \text { SD }\left(\mu \mathrm{g} \mathrm{mL} \mathrm{mL}^{-1}\right)\end{array}$ & $\begin{array}{c}\text { Quercetin } \\
\text { Mean } \pm \mathrm{SD}\left(\mu \mathrm{g} \mathrm{mL} \mathrm{m}^{-1}\right)\end{array}$ \\
\hline \multicolumn{3}{|c|}{ Oils } \\
\hline \multicolumn{3}{|c|}{ Long-chain triglycerides } \\
\hline Sesame oil & $2.85 \pm 0.04$ & $1.75 \pm 0.02$ \\
\hline Olive oil & $2.86 \pm 0.07$ & $1.54 \pm 0.02$ \\
\hline Soybean oil & $2.74 \pm 0.02$ & $1.57 \pm 0.03$ \\
\hline \multicolumn{3}{|c|}{ Medium-chain triglycerides } \\
\hline Crodamol $^{\mathrm{TM}} \mathrm{PC}$ & $3.35 \pm 0.01$ & $2.05 \pm 0.02$ \\
\hline \multicolumn{3}{|c|}{ Other } \\
\hline Oleic acid & $2.76 \pm 0.06$ & $1.65 \pm 0.02$ \\
\hline \multicolumn{3}{|c|}{ Surfactants } \\
\hline \multicolumn{3}{|c|}{ Polyoxyethylene castor oil derivatrives } \\
\hline Cremophor ${ }^{\circledR}$ RH 40 & $6.90 \pm 0.01$ & $1.73 \pm 0.02$ \\
\hline \multicolumn{3}{|c|}{ Polyoxyethylene sorbitan fatty acid esters } \\
\hline Tween ${ }^{\circledR} 80$ & $4.30 \pm 0.46$ & $1.75 \pm 0.02$ \\
\hline \multicolumn{3}{|c|}{ Co-solvents } \\
\hline PEG 400 & $6.76 \pm 0.09$ & $14.12 \pm 2.18$ \\
\hline Propylene glycol & $3.11 \pm 0.05$ & $2.44 \pm 0.09$ \\
\hline Water & $1.07 \pm 0.01$ & $1.03 \pm 0.11$ \\
\hline
\end{tabular}

$\mathrm{SD}$ - standard deviation. The test was performed in triplicate.

Ternary phase diagram was used to determine the ratios of oil, surfactant, and cosolvent that resulted in the generation of stable SMEDDS formulations and microemulsions after SMEDDS dilution. The gray area in the ternary phase diagram represents the composition percentage that produced a microemulsion after dilution of the visual grade I (Fig. 1). A comparison of self-microemulsification areas of Fig. 1A-D revealed system A, consisting of sesame oil, Cremophor ${ }^{\circledR}$ RH 40, and PEG 400, to form a larger self-microemulsification area compared to systems B, C, and D. However, system A resulted in a microemulsion at an oil phase concentration of up to $10 \%$. This could also be found in system $\mathrm{B}$. Thus, it could be concluded that the combination of oil and Crodamol ${ }^{\mathrm{TM}} \mathrm{PC}$, with Tween ${ }^{\circledR}$ 80 as a surfactant, produced SMEDDS with visual grade I until the oil phase was up to 20 $\%$. In the system containing Crodamol ${ }^{\mathrm{TM}}$ PC and Tween ${ }^{\circledR}$ 80, the co-solvent, PEG 400 or propylene glycol could be used (systems $C$ and D). In these systems, the self-emulsification area aided by PEG 400 or propylene glycol was not significantly different. Therefore, SMEDDS formulations were prepared according to the ternary phase diagrams. Firstly, eight different formulations of SMEDDS were prepared without M. oleifera extract to select optimal formulations based on the size of the microemulsion droplet and the ability to emulsify in the medium after further addition of the extract. 


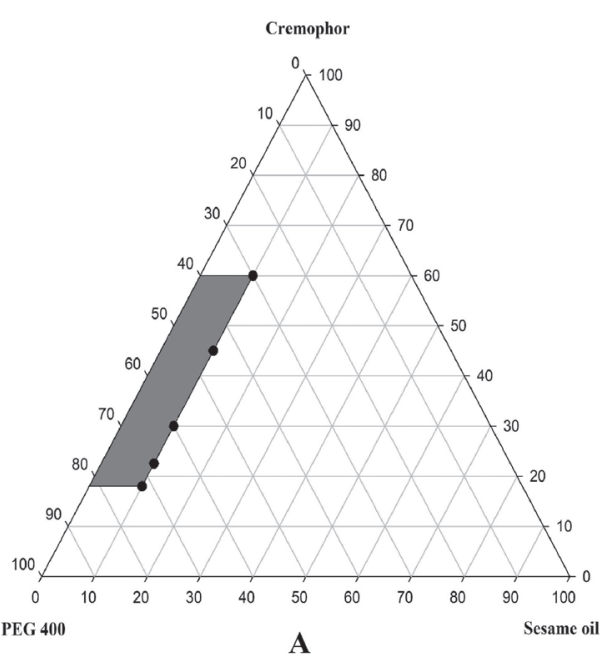

PEG 400

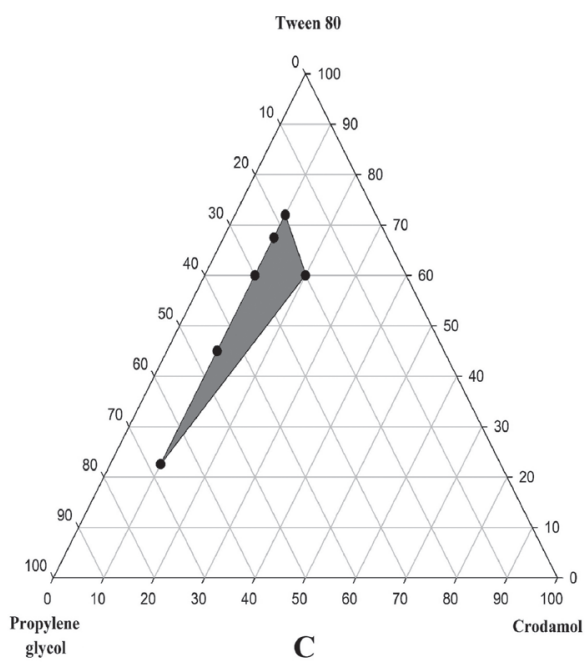

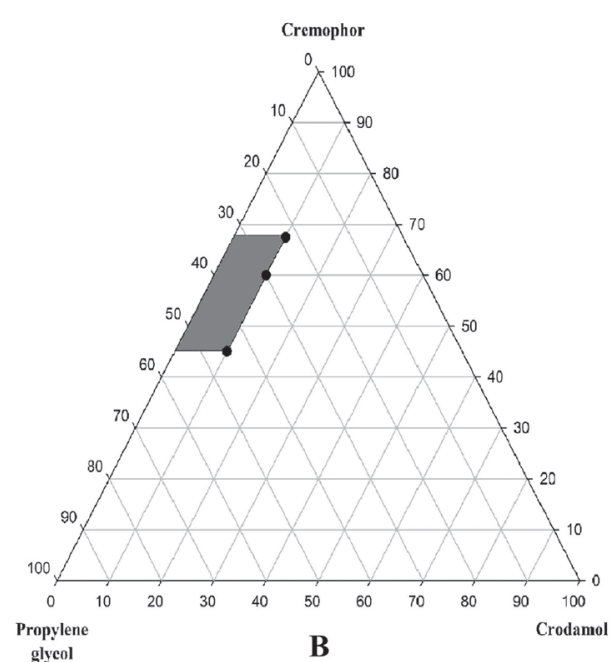

Tween 80

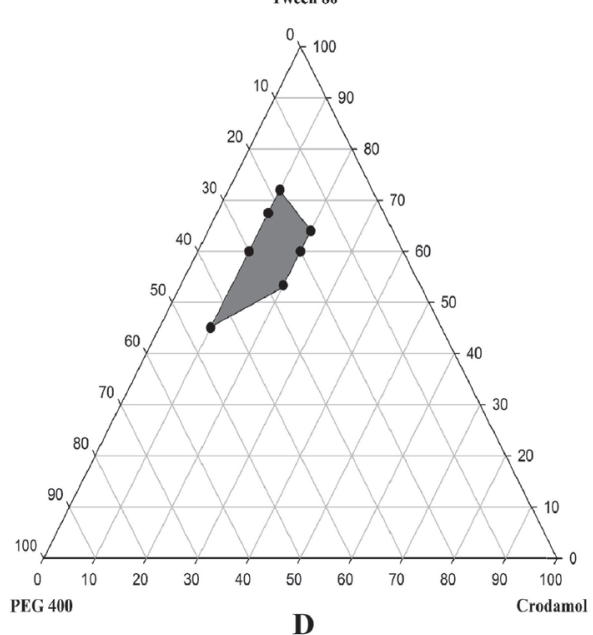

Fig. 1. Ternary phase diagram of system A (Sesame oil/Cremophor ${ }^{\circledR}$ RH 40/ PEG 400); System B (Crodamol $^{\mathrm{TM}}$ PC/Cremophor ${ }^{\circledR}$ RH 40/Propylene glycol); system C (Crodamol ${ }^{\mathrm{TM}}$ PC/Tween ${ }^{\circledR}$ 80/Propylene glycol); system D (Crodamol ${ }^{\mathrm{TM}} \mathrm{PC} /$ Tween $^{\circledR}$ 80/PEG 400). Gray areas represent the self-microemulsification area with visual grade I.

\section{Physical properties of SMEDDS}

SMEDDS formulations that contained more than $20 \%$ of oil phase and exhibited a self-emulsification performance of Grades I and II were selected to determine the emulsion droplet size. The emulsion droplet size (Z-Ave \pm SD) and PDI of SMEDDS formulations are shown in Table II. 
N. Sermkaew and T. Plyduang: Self-microemulsifying drug delivery systems of Moringa oleifera extract for enhanced dissolution of kaempferol and quercetin, Acta Pharm. 70 (2020) 77-88.

Table II. Visual grading and droplet size of SMEDDS formulations composed of oil, surfactant and co-solvent

\begin{tabular}{|c|c|c|c|c|c|c|c|c|c|}
\hline \multirow[b]{2}{*}{ No. } & \multicolumn{6}{|c|}{ Composition $(\%, m / m)$} & \multirow[b]{2}{*}{$\begin{array}{l}\text { Visual } \\
\text { grading }\end{array}$} & \multirow{2}{*}{$\begin{array}{l}\text { Z-Ave } \pm \text { SD }^{a} \\
\text { (d.nm) }\end{array}$} & \multirow[b]{2}{*}{ PDI } \\
\hline & $\begin{array}{c}\text { Sesame } \\
\text { oil }\end{array}$ & $\begin{array}{c}\text { Crodamol }^{\mathrm{TM}} \\
\text { PC }\end{array}$ & $\begin{array}{l}\text { Cremophor }^{\circledR} \\
\text { RH } 40\end{array}$ & $\begin{array}{l}\text { Tween }^{\circledast} \\
80\end{array}$ & $\begin{array}{c}\text { PEG } \\
400\end{array}$ & $\begin{array}{c}\text { Propylene } \\
\text { glycol }\end{array}$ & & & \\
\hline $\mathrm{F} 1$ & 20 & & 64 & & 16 & & 2 & $161.07 \pm 46.03$ & 0.41 \\
\hline F2 & & 20 & & 53.3 & 26.7 & & 1 & $34.93 \pm 12.33$ & 0.38 \\
\hline F3 & & 20 & & 60 & 20 & & 1 & $26.39 \pm 2.54$ & 0.26 \\
\hline $\mathrm{F} 4$ & & 20 & & 64 & 16 & & 1 & $25.89 \pm 3.20$ & 0.23 \\
\hline F5 & & 30 & & 52.5 & 17.5 & & 2 & $40.48 \pm 4.13$ & 0.21 \\
\hline F6 & & 30 & & 56 & 14 & & 2 & $34.62 \pm 2.34$ & 0.21 \\
\hline F7 & & 20 & & 53.3 & & 26.7 & 2 & $31.67 \pm 2.74$ & 0.28 \\
\hline F8 & & 20 & & 60 & & 20 & 1 & $33.20 \pm 3.43$ & 0.31 \\
\hline F9 & & 20 & & 64 & & 16 & 2 & $23.20 \pm 1.82$ & 0.27 \\
\hline
\end{tabular}

a The test was performed in triplicate. Z-Ave - the averaged diameter of microemulsion (nm). PDI - the polydispersity index.

The M. oleifera extract of $10 \%$ by weight was added to the SMEDDS formulation, which resulted in a microemulsion with a droplet size of less than $50 \mathrm{~nm}$ after dilution. Smaller droplet size resulted in a larger surface area; resulting in a more efficient in vivo absorption. Formulations F2 to F9 were therefore selected. SMEDDS formulations with $M$. oleifera extract were then evaluated for their potential to self-emulsify and microemulsion droplet size to confirm if these properties were affected by the extract. After addition of 10 $\%$ extract to SMEDDS formulations, only formulations F3 and F8 could rapidly disperse when introduced into water, exhibiting good self-emulsification of visual grade I.

Based on SMEDDS properties, formulations F3 and F8 were selected for dissolution studies. Emulsification time of formulation F3 was calculated to be $48 \mathrm{~s}$, whereas it was $60 \mathrm{~s}$ for formulation F8. This finding indicated that SMEDDS, composed of PEG 400 as co-solvent, helped in a more rapid emulsification than the system containing propylene glycol. This is due to the higher solubilizing capacity of PEG 400 than that of propylene glycol. Both F3

Table III. Visual grading and droplet size of SMEDDS formulations containing M. oleifera crude extract

\begin{tabular}{ccccccc}
\hline & \multicolumn{5}{c}{ Composition $(\%, m / m)$} & Z-Ave \pm SD $^{\text {a }}$ \\
No. & $\begin{array}{c}\text { Crodamol } \\
\text { PC }\end{array}$ & Tween $^{\circledR} 80$ & $\begin{array}{c}\text { PEG } \\
400\end{array}$ & $\begin{array}{c}\text { Propylene } \\
\text { glycol }\end{array}$ & PDI \\
\hline F3 & 20 & 60 & 20 & & $48.95 \pm 15.09$ & 0.257 \\
F8 & 20 & 60 & & 20 & $62.10 \pm 18.28$ & 0.410 \\
\hline
\end{tabular}

a The test was performed in triplicate. Z-Ave - the averaged diameter of microemulsion. PDI - the polydispersity index. 
a)

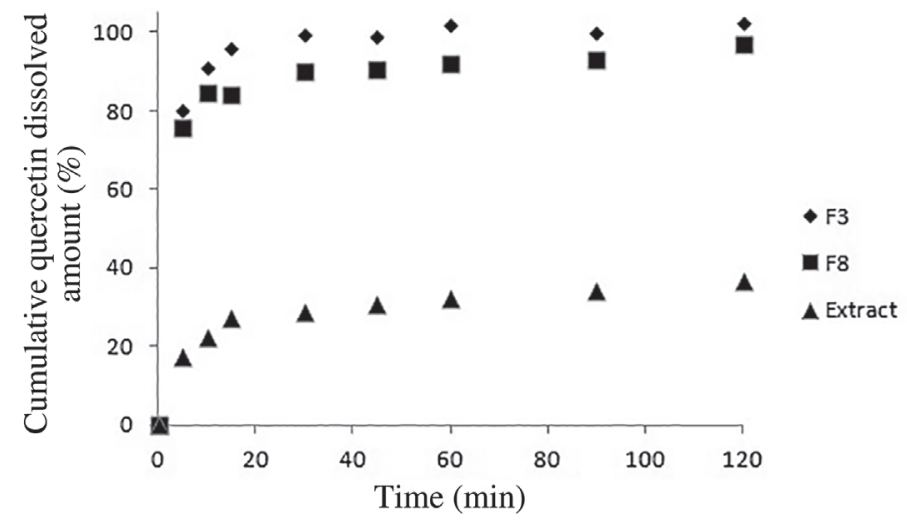

b)

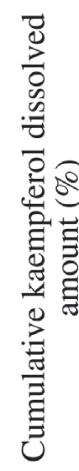

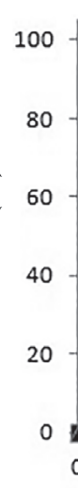
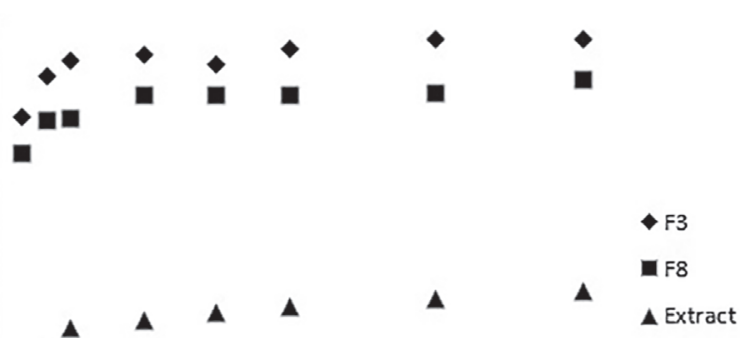

Fig. 2. Dissolution profiles of F3 and F8 SMEDDS formulations compared to the unformulated extract in simulated gastric fluid ( $\mathrm{pH}$ 1.2) without pepsin. The cumulative dissolved amount of: a) quercetin and b) kaempferol.

and F8 exhibited self-emulsification visual grading of Grade I; however, F3 consisting of PEG 400 as co-solvent could emulsify within 20 s, whereas F8 (propylene glycol as co-solvent) emulsified within $50 \mathrm{~s}$ (data not shown). Therefore, better solubilizing and self-emulsification abilities could be the reason for the smaller size of microemulsions resulting from F3 dilution in water. The microemulsion droplet size of both formulations was slightly increased after addition of the extract. However, the microemulsion droplet size of F3 was smaller than that of F8 (Table III). Increase in the microemulsion droplet size after addition of the extract could be an effect of decreased availability of the surfactant to reduce droplet size (21).

Emulsification performance and microemulsion droplet size were affected by the types of co-solvents comprising SMEDDS, and the length of hydrophobic chains in them. The present study revealed that the system consisting of a co-solvent with longer chain length, such as PEG 400, yielded microemulsion droplets with smaller size compared to propylene 
glycol. The effect of chain length of co-solvents on microemulsion formation has also been reported by Abd Sisak et al. (2017), who used three co-solvents, PEG 400 (long chain), Transcutol $^{\circledR}$ (medium chain), and propylene glycol (short chain). It was found that the co-solvent with medium chains was the most suitable, followed by those containing short and long chains in a system containing oleic acid and polyoxyethylene-10-oleyl ether (22).

The amount of kaempferol and quercetin in formulations F3 and F8 was calculated to be 0.15 and $0.12 \%(\mathrm{~m} / \mathrm{m})$ and 0.14 and $0.09 \%(\mathrm{~m} / \mathrm{m})$, respectively. Self-microemulsifying formulations enhanced the solubility of $M$. oleifera crude extract. Consequently, formulations F3 and F8 had a higher content of kaempferol and quercetin than the crude extract (consisting of $0.0047 \%$ of kaempferol and $0.0025 \%$ of quercetin).

\section{In vitro dissolution test}

The dissolution profile of SMEDDS formulations F3 and F8 is shown in Fig. 2. Rapid dissolution of the two compounds was observed over the initial $5 \mathrm{~min}$, with approximately $100 \%$ dissolution after $15 \mathrm{~min}$. On the other hand, dissolution of kaempferol and quercetin from the unformulated crude extract increased slowly up to $30 \%$ in $1 \mathrm{~h}$. The F3 formulation comprising PEG 400 as co-solvent displayed a faster dissolution rate and consequently a larger dissolved amount of kaempferol and quercetin at all time points. This could be attributed to rapid emulsification and smaller size of microemulsion droplets of F3 compared to that of F8. These findings showed that SMEDDS could enhance the rate and extent of dissolution of the active compounds, kaempferol and quercetin, in the $M$. oleifera extract by approximately three times.

\section{CONCLUSIONS}

The present study describes the development of a self-microemulsifying system of $M$. oleifera leaf extract for enhanced oral delivery of its active constituents, kaempferol and quercetin. Composition of the optimized formulation (F3) was $20 \mathrm{~g} \mathrm{Crodamol}^{\mathrm{TM}}$ PC, $60 \mathrm{~g}^{\text {Tween }}{ }^{\circledR}$ 80, $20 \mathrm{~g}$ PEG 400, and $10 \mathrm{~g}$ M. oleifera extract. Formulation F3 rapidly dispersed in the medium to form microemulsions having a droplet size of approximately $49 \mathrm{~nm}$. The SMEDDS formulation of M. oleifera extract exhibited a three-fold greater dissolution of the active compounds compared to the unformulated extract. Thus, it could be concluded that SMEDDS could serve as a promising strategy for the oral delivery of $M$. oleifera extract-derived drugs.

Acknowledgement. - Financial support was granted by Walailak University (Grant No. WU61112).

\section{REFERENCES}

1. Y. Liu, X. Y. Wang, X. M. Wei, Z. T. Gao and J. P. Han, Values, properties and utility of different parts of Moringa oleifera : An overview, CHM. 10 (2018) 371-378. https://doi.org/10.1016/j. chmed.2018.09.002

2. N. Qi, Gong. X, C. Feng, X. Wang, Y. Xu and L. Lin, Simultaneous analysis of eight vitamin E isomers in Moringa oleifera Lam. leaves by ultra performance convergence chromatography, Food Chem. 207 (2016) 157-161; https://doi.org/10.1016/j.foodchem.2016.03.089 
N. Sermkaew and T. Plyduang: Self-microemulsifying drug delivery systems of Moringa oleifera extract for enhanced dissolution of kaempferol and quercetin, Acta Pharm. 70 (2020) 77-88.

3. B. Moyo, S. Oyedemi, P. J. Masika and V. Muchenje, Polyphenolic content and antioxidant properties of Moringa oleifera leaf extracts and enzymatic activity of liver from goats supplemented with Moringa oleifera leaves/sunflower seed cake, Meat Sci. 91 (2012) 441-447; https://doi.org/10.1016/j. meatsci.2012.02.029

4. D. Jaiswal, P. K. Rai, A. Kumar, S. Mehta and G. Watal, Effect of Moringa oleifera Lam. leaves aqueous extract therapy on hyperglycemic rats, J. Ethnopharmacol. 123 (2009) 392-396; https://doi. org/10.1016/j.jep.2009.03.036

5. P. Chumark, P. Khunawat, Y. Sanvarinda, S. Phornchirasilp, N. P. Morales, L. Phivthong-ngam, P. Ratanachamnong, S. Srisawat and K. S. Pongrapeeporn, The in vitro and ex vivo antioxidant properties, hypolipidaemic and antiatherosclerotic activities of water extract of Moringa oleifera Lam. Leaves, J. Ethnopharmacol. 116 (2008) 439-446; https://doi.org/10.1016/j.jep.2007.12.010

6. S. Charoensin, Antioxidant and anticancer activities of Moringa oleifera leaves, J. Med. Plants Res. 8 (2014) 318-325; https://doi.org/10.5897/JMPR2013.5353

7. L. L. Jung, Soluble extract from Moringa oleifera leaves with a new anticancer activity, Plos One 9 (2014) e95492; https://doi.org/10.1371/journal.pone.0095492

8. S. Sreelatha, A. Jeyachitra and P. R. Padma, Antiproliferation and induction of apoptosis by Moringa oleifera leaf extract on human cancer cells, Food Chem. Toxicol. 49 (2011) 1270-1275; https://doi. org/10.1016/j.fct.2011.03.006

9. PubChem Identifier: CID 5280863; https://pubchem.ncbi.nlm.nih.gov/compound/5280863; access date February 26, 2019.

10. A. Barve, C. Chen, V. Hebbar, J. Desiderio, C. L. L. Saw and A. N. Kong, Metabolism, oral bioavailability and pharmacokinetics of chemopreventive kaempferol in rats, Biopharm. Drug Dispos. 30 (2009) 356-365; https://doi.org/10.1002/bdd.677

11. L. Gao, G. Liu, X. Wang, F. Liu, Y. Xu and J. Ma, Preparation of a chemically stable quercetin formulation using nanosuspension technology, Int. J. Pharm. 404 (2011) 231-237; https://doi. org/10.1016/j.ijpharm.2010.11.009

12. K. A. Khaled, Y. M. El-Sayed and B. M. Al-Hadiya, Disposition of the flavonoid quercetin in rats after single intravenous and oral doses, Drug Dev. Ind. Pharm. 29 (2003) 397-403; https://doi. org/10.1081/DDC-120018375

13. R. Gugler, M. Leschik and H. J. Dengler, Disposition of quercetin in man after single oral and intravenous doses, Eur. J. Clin. Pharmacol. 9 (1975) 229-234.

14. K. Zhang, L. Gu, J. Chen, Y. Zhang, Y. Jiang, L. Zhao, K. Bi and X. Chen, Preparation and evaluation of kaempferol-phospholipid complex for pharmacokinetics and bioavailability in SD rats, J. Pharm. Biomed. Anal. 114 (2015) 168-175; https://doi.org/10.1016/j.jpba.2015.05.017

15. K. Zhang, M. Zhang, Z. Liu, Y. Zhang, L. Gu, G. Hu, X. Chen and J. Jia, Development of quercetinphospholipid complex to improve the bioavailability and protection effects against carbon tetrachloride-induced hepatotoxicity in SD rats, Fitoterapia 113 (2016) 102-109; https://doi.org 10.1016/j. fitote.2016.07.008

16. R. Pangeni, S. W. Kang, M. Oak, E. Y. Park and J. W. Park, Oral delivery of quercetin in oil-inwater nanoemulsion: In vitro characterization and in vivo anti-obesity efficacy in mice, J. Funct. Foods 38 (2017) 571-581; https://doi.org/10.1016/j.jff.2017.09.059

17. K. AboulFotouh, A. A. Allam, M. El-Badry and A. M. El-Sayed, Role of self-emulsifying drug delivery systems in optimizing the oral delivery of hydrophilic macromolecules and reducing interindividual variability, Colloids Surf. B Biointerfaces 167 (2018) 82-92; https://doi.org/10.1016/j. colsurfb.2018.03.034

18. R. N. Gursoy and S. Benita, Self-emulsifying drug delivery systems (SEDDS) for improved oral bioavailability of lipophilic drugs, Biomed. Pharmacother. 58 (2004) 173-182; https://doi.org/10.1016/j. biopha.2004.02.001 
19. S. Setthacheewakul, S. Mahattanadul, N. Phadoongsombut, W. Pichayakorn and R. Wiwattanapatapee, Development and evaluation of self-microemulsifying liquid and pellet formulations of curcumin, and absorption studies in rats, Eur. J. Pharm. Biopharm. 76 (2010) 475-485; https://doi. org/10.1016/j.ejpb.2010.07.011

20. A. K. Nayak and P. P. Panigrahi, Solubility enhancement of etoricoxib by cosolvency approach, ISRN. 2012 (2012) 1-5, http://dx.doi.org/10.5402/2012/820653

21. M. M. Bandivadeka, S. S. Pancholi, R. Kaul-Ghanekar, A. Choudhari and S. Koppikar, Self-microemulsifying smaller molecular volume oil (Capmul MCM) using non-ionic surfactants: a delivery system for poorly water-soluble drug, Drug Dev. Ind. Pharm. 38 (2012) 883-892, https://doi.org/10. 3109/03639045.2011.631548

22. M. A. Abd Sisak, R. Daik and S. Ramli, Study on the effect of oil phase and co-surfactant on microemulsion systems, MJAS 21 (2017) 1409-1416; https://doi.org/10.17576/mjas-2017-2106-23 